\title{
Cavanilles y Zea: una amistad político-científica
}

\author{
DiAnA SOTO ARANGO
}

\section{Introducción}

La amistad que se estableció entre Francisco Antonio Zea y Antonio José Cavanilles se analizara en este articulo utilizando la correspondencia inédita de Zea. También se reconstruye este vínculo con cartas de José Celestino Mutis, Ignacio Pombo, Francisco José de Caldas, José María Cabal y del mismo Cavanilles.

Las cartas de Zea a Cavanilles se han conservado casi en su totalidad. Pero, en cambio, no hemos localizado las que Cavanilles le envío al neogranadino, aunque nos ha sido posible rehacer las impresiones que tenían los dos sobre el grupo de botánicos de la metrópoli y americanos.

La importancia de los documentos señalados radica en el conocimiento que se puede tener sobre la vida privada de Zea, sus estudios, trabajos científicos y en especial el ambiente y la participación del antioqueño en la polémica entre Cavanilles y Ortega.

El primer contacto académico se inicia en 1798, cuando Zea estaba preso en Cádiz, y se convirtió pronto en una amistad de protección por parte de Cavanilles. Esta actitud se mantiene hasta 1804, cuando muere Cavanilles y Zea pasa a ocupar su lugar en la dirección del Real Jardín Botánico de Madrid. 


\section{Zea de sub-director de la Expedición Botánica a presidiario en Cádiz}

Francisco Antonio Zea (1766-1822) nació en la villa de Medellín ${ }^{1}$, y por ser hijo de nobles pudo inscribirse como estudiante del Colegio de Popayán donde fue discípulo del ilustrado José Félix Restrepo (1760-1832) ${ }^{2}$. Además, el haber ingresado como colegial en el Mayor de San Bartolomé de Santa Fe le permitió pertenecer a lo más selecto de sociedad neogranadina; es decir, a la élite ilustrada de la época. En Popayán tuvo como condiscípulos a Francisco José de Caldas (1768-1816) y a Camilo Torres (1766-1816) y en Santa Fe se vinculó con la nueva generación que debatía las modernas concepciones filosóficas y políticas.

En el Colegio de San Bartolomé, finalizados sus estudios, inició su vida profesional como catedrático de gramática en 1788. Este joven profesor, dedicado totalmente a su magisterio ${ }^{3}$, pronto empezó a impartir clases de latín, francés, matemáticas y ciencias naturales. Su prestigio profesional llegó a oídos del virrey José de Ezpeleta quien, en 1791, le encargó la educación de sus hijos, nombrándole, más tarde, sub-director de la Expedición Botánica de Santa Fe.

Zea inició sus actividades botánicas al lado del gaditano José Celestino Mutis (1732-1808), trabajando como Segundo Agregado de la Expedición Botánica de Santa Fe. Años después, en la inauguración del curso de Botánica en el Real Jardín Botánico de Madrid señalaba: «Debo a Mutis infinito agradecimiento, no solo por haber sido su discípulo más querido, haber vivido en su casa sin separarme de su lado y haber recibido de su mano continuos beneficios, sino también por los servicios inmortales que ha hecho a todo el Nuevo reino de Granada» ${ }^{4}$. Zea comentaría en sus escritos europeos siempre la época de su formación al lado de Mutis, y no olvidó la vegetación y la fauna de la zona de Fusagasugá, donde desarrolló sus observaciones como miembro de la Expedición.

1. Zea nació en la villa de Medellín, el 23 de noviembre de 1766 y murió el 28 de noviembre de 1822 en el York House Hotel, de la ciudad de Bath, Inglaterra, a la edad de 51 años. Zea siempre quiso regresar a su ciudad natal pero murió sin poder cumplir este deseo.

${ }^{2}$ Félix Restrepo nació en Medellín el 28 de noviembre de 1760 y murió en Bogotá el 22 de septiembre de 1832. En octubre de 1782, cuando Zea iba a cumplir sus diez y seis años, viajó con Félix Restrepo a iniciar sus estudios en el Real Colegio y Seminario de Popayán. Botero Saldarriaga, R. (1945). Francisco Antonio Zea. Bogotá, Ediciones del Consejo, p. 28.

3 . Así lo manifiestan las diferentes cartas de José María Cabal donde detalla la dedicación que Francisco Antonio Zea le otorgaba. En carta del 15 de enero de 1793 le informaba Cabal a su padre: "Sólo le digo que una parte de mi lucimiento se la debo a mi amigo Zea. El se interesa en mis asuntos como si fuesen propios. Se ha empeñado en erigirme una fama igual a la suya. Yo no dudo conseguirla porque él es el arbitro en esto". TASCON, T. E. (1930). Nueva biografía del general José María Cabal. Bogotá, Minerva, p. 51.

${ }^{4}$ ZEA, F. A. (1805). Discurso acerca del método y utilización de la botánica. Madrid, Imprenta Real, pp. 40-41. 
La cercanía de la pequeña población a Santa Fe le permitía viajar constantemente a la capital e integrarse plenamente en las actividades culturales de la ciudad santafereña, participando en la tertulia El Arcano de la Filantro-

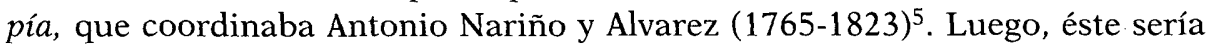
el motivo principal para ser catalogado como subversivo ante la corona, provocando su detención.

Zea estuvo preso en Cádiz ${ }^{6}$, desde 1795 a 1799, aunque al año de llegar se le dio la ciudad por prisión. Durante su estancia en Cádiz se alojó primero en la calle Portal de Paños y luego en la calle del Fideo n. ${ }^{\circ} 18$; actualmente llamada calle Enrique de las Marinas, ubicada en el centro de la ciudad. Si algo caracterizó la personalidad de Zea fue su espíritu optimista, práctico y su capacidad para relacionarse con el poder. Esta última actitud la denominó José Ignacio de Pombo (1761-1815) ${ }^{7}$ de «carácter intrigante y cortesano". Mientras su compañeros de presidio se quejaban de su situación económica, Zea se dolía de su enfermedad, que se agravaba en la época de invierno.

La descripción más detallada del cautiverio de Zea la hemos encontrado en las cartas que su amigo José María Cabal (1769-1816) ${ }^{8}$ envió a su familia. Cabal describe a su amigo como una persona que lleva la prisión con paciencia y conformidad 9 .

\footnotetext{
5 A esta tertulia asistieron Nariño, su organizador, José María Lozano, José Antonio Ricaurte, José Luis Anzola, Juan Esteban Ricaurte, Francisco Zea, Francisco Tovar, Joaquín Camacho, Andrés José de Iriarte. Nariño publicó los Derechos del Hombre en 1793. ANTOLínez Camargo, R. (1991) El Papel Periódico de Santafé de Bogotá. 1791-1797. Bogotá, Biblioteca Banco Popular, pp. 51-52.

${ }^{6}$ A Zea se le detiene en marzo de 1795. El 3 de noviembre sale de Santa Fe y el 24 del mismo mes le embarcan desde Cartagena hacia la Habana adonde llega el 12 de diciembre. El 22 de enero de 1796 le envían para Cádiz y llega el 18 de marzo preso y enfermo de paludismo. En junio de 1799 el Consejo dictaminó que podía regresar a su tierra natal.

7 José Ignacio de Pombo nació en Popayán en 1761, estudió filosofía y derecho en el Colegio del Rosario de Santa Fe y se estableció como comerciante en Cartagena hacia 1780 ó 1784 donde ocupó diverso cargos públicos. Fue uno de los comerciantes más poderosos por el volumen de sus importaciones. Apoyó a Caldas y logró el establecimiento del Jardín Botánico de Cartagena y una escuela de dibujo y pilotaje. Murió en 1815. PomBo, J.I. (1986). Comercio y contrabando en Cartagena de Indias. Bogotá, Nueva Biblioteca Colombiana de Cultura, Procultura.

8 José María Cabal nace en 1769 en la ciudad de Buga. Cabal ingresa en 1785 al Colegio Real y Seminario de.Popayán, precisamente en el último año de estudios de Zea en esta Institución. En 1791 pasa a Santa Fe a estudiar en el Colegio de San Bartolomé donde Zea ya era profesor y toma a Cabal bajo su tutoría. En las cartas de.Cabal a su padre le manifestaba que él no hacía cosa alguna sin consultarlo con su amigo Zea. TASCón, T. E. (1930), pp. 32-49.

9 Decía Cabal: «Zea desde la Habana ha tenido calenturas hasta ahora poco que se le han quitado. Los dos no nos hemos separado nunca y cada día nos amamos más». Carta de Cádiz del 17 de junio de 1796. Ibidem., p. 109.
} 
Zea manifestó siempre que su cárcel se debía a las calumnias de sus enemigos $^{10}$. Pero durante su cautiverio recibió manifestaciones de apoyo, entre otras las de José Celestino Mutis y Antonio Cavanilles y, también, actitudes disonantes y oportunistas como la de Francisco José de Caldas. Caldas, cuando se expatrió a Zea, le atacó tratándolo despectivamente por pertenecer al grupo de los pasquines ${ }^{11}$, y a su vez intrigó para obtener el cargo que tenía Zea en la Expedición ${ }^{12}$. Pero luego, no tuvo inconveniente en cambiar su posición ${ }^{13}$ y ofrecerse a trabajar bajo la dirección de Zea cuando se le informa que éste regresaría a Santa Fe. Finalmente, cuando se confirma que Zea se queda trabajando en España, Caldas, otra vez, moviliza a sus amigos para obtener el cargo que aquel ocupaba en la Expedición Botánica de Santa $\mathrm{Fe}^{14}$. Pero no consiguió su objetivo ${ }^{15}$, porque Caldas no logró de Mutis el mismo apoyo que el sabio le había dado a Zea ${ }^{16}$.

El criollo Zea le escribe a Antonio José Cavanilles (1745-1804) en su condición de aficionado a la botánica que desea formarse con el amigo de su maestro Mutis. La correspondencia epistolar con el sabio Cavanilles se inicia el 20 de junio de 1798, desde la ciudad de Cádiz, cuando aun no se había definido su situación de preso político.

Para Zea era importante demostrarle a Cavanilles que él era protegido de Mutis y que fue éste quien le indujo al estudio de la botánica y lo llevó a trabajar en la Subdirección de la Expedición Botánica de Santa Fe. Su deseo era reincorporarse a los estudios y tareas al lado de su maestro. A pesar de la crí-

\footnotetext{
10 Primera carta de Zea a Cavanilles del 20 de junio de 1798 desde Cádiz. Zea le envía desde Cádiz a Cavanilles 18 cartas. La primera data del 20 de junio de 1798 y la última del 2 de enero de 1800. Archivo de Antonio Cavanilles (AAC), Legajo 24, carpeta 4, Archivo Jardín Botánico ( $A J B)$. La carta del anexo y las notas de las mismas se transcriben con la ortografía original de los documentos. Sólo hemos cambiado la escritura de los nombres propios cuando hemos identificado al personaje y su denominación no era correcta. Estas cartas de ahora en adelante aparecerán según numeración nuestra de la primera a la 31.

11 Carta de Caldas a Santiago Jagua de diciembre de 1796. Caldas, F. (1978). Cartas de Caldas. Bogotá, Academia Colombiana de Ciencias Exactas, Físicas y Naturales, p. 26.

12 Carta de Caldas a Santiago Pérez. Popayán 20 de julio de 1801. Ibidem., p. 88.

13 Carta de Caldas a Santiago Pérez. Popayán, abril de 1801. Ibidem., p. 63.

14 Carta de Caldas a Santiago Pérez. Quito, 6 de mayo de 1802. Ibidem., p. 177.

15 Carta a Santiago Pérez de febrero de 1804 y de septiembre, 30 de 1808. Ibidem., pp. 237 y 81 .

${ }_{16}$ Zea le comenta a Cavanilles: «Estudiaba leyes en aquella universidad en la cual era catedrático de Humanidades, cuando Mutis fue a solicitarme, ó como dice él mismo en su informe al Rey á, conquistarme para la Botánica. En efecto fui por su solicitud agregado a su expedición con el destino a sucederle en la dirección de ella y continuar sus obras. Dos años estuve en su casa instruyéndome en la Facultad, y otro pasé en una montaña solitaria haciendo excursiones botánicas». Carta de Zea a Cavanilles, Cádiz, 20 de junio de 1798. Carta n. ${ }^{\circ} 1$, «numeración nuestra».
} 


\section{CAVANILLES Y ZEA: UNA AMISTAD POLITICO-CIENTIFICA}

tica condición de presidiario, Zea mostraba su satisfacción porque las tramas de sus enemigos no lo habian privado de la amistad del Dr. Mutis, por más que lo intentaron.

En las cartas enviadas, desde Cádiz, se reflejan varios aspectos: descripción de plantas americanas; informes sobre las actividades de Mutis en el virreinato de la Nueva Granada; demostraciones de la gran amistad que tiene con Mutis y la admiración que profesa a su maestro; informes sobre los botánicos y personas sobresalientes de Santa Fe; ataca a Hipólito Ruiz López (1752-1816), a José Antonio Pavón Jiménez (1754-1840) y expone conceptos negativos sobre el curso de botánica de Casimiro Gómez Ortega (1740-1818) y sobre la obra que publicó en 1799; promete a Cavanilles que si el regresa a América, será un fiel informante y, en especial, le garantiza el envío de las codiciadas plantas americanas.

También puede deducirse de estas cartas que, posiblemente, Mutis le hubiera informado sobre las divergencias entre los científicos botánicos de la metrópoli. Ademas, el criollo conocía el Prodromo de la Flora Peruana «y la colección de papeles sobre la controversia» que se los había remitido a Mutis desde Cádiz.

La amistad entre ambos botánicos se remontaba a 1786, cuando Mutis le comenta que le dedicará una planta en su próxima publicación de la Flora de Santa $\mathrm{Fe}^{17}$. Esta correspondencia entre Mutis y Cavanilles se caracteriza por los comentarios políticos y académicos. Cavanilles alertó a Mutis de las actuaciones que Ortega realizaba en su contra y el gaditano tomó posición al lado de su amigo Cavanilles ${ }^{18}$. Además, en esta relación epistolar se piden favores mutuos. Mutis le solicita que le remita $\operatorname{libros}^{19}$ y Cavanilles que le envíe semillas y plantas para el Jardín Botánico de Madrid.

Por su parte, Zea pronto asumió el papel que consideró le correspondía en su relación con Cavanilles. El botánico metropolitano, en su polémica con Ortega, necesitaba una pluma ágil, que tuviera el conocimiento de las plantas americanas. Zea reunía estas condiciones y se puso al servicio de los intereses de Cavanilles dirigiendo en primer plano sus escritos contra Ortega y los

17 «Primera carta que le envía Mutis a Cavanilles donde le comunica que le dedicará una planta en su próxima publicación de la Flora de Santa Fe. 2 de octubre de 1786, Mariquita. Dice Mutis: "Sería muy culpable mi silencio si ahora, que por primera vez se me presenta la ocasión de saludar a Vuesamerced, lo dejara más tiempo". HernándeZ DE AlBA, G. (1983). Archivo Epistolar del sabio naturalista don José Celestino Mutis. Bogotá, Editorial Presencia Ltda. Tomo I, pp. 349.

18 Carta de Mutis a Cavanilles del 19 de agosto de 1794, Santa Fe. Hernández de Alba, G. (1983), Tomo II, pp. 105 a 107.

19 "Carta de Mutis donde le pide a Cavanilles le envíe libros porque no está satisfecho con su corresponsal en Cádiz José María Lasquetti. Santa Fe, 19 de enero de 1795». Ibidem., p. 107.

Asclepio-Vol. XLVII-1-1995 


\section{DIANA SOTO ARANGO}

expedicionarios peruanos. El criollo demostró elocuencia política, burla irreverente, sarcasmo e ironía, en los juicios formulados sobre Ortega en la correspondencia.

El antioqueño, como escritor, se había formado bajo los acontecimientos políticos de un virreinato en el que su élite criolla clamaba por transformaciones económicas y culturales. El primer artículo lo publicó bajo el titulo de "Avisos de Hebephilo»" 20 que editó en Papel Periódico. Este primer escrito correspondió a la dinámica de la discusión sobre la enseñanza que en ese momento se estaba realizando en los Colegios Mayores del Rosario y de San Bartolomé.

Mientras tanto, desde Cádiz, Zea había reiniciado su vida académica, primero con un curso de botánica en el Hospital y luego con el intercambio científico que realizó con Cavanilles. Un hecho que resalta en esta correspondencia es que la situación de alumno-maestro se comenzó a modificar rápidamente al convertirse el antioqueño en informante científico y político. En efecto, Cavanilles hizo constar en sus escritos cada una de las informaciones botánicas ${ }^{21}$ que recibía de Zea y también el hecho de haberle vinculado al grupo de sus amistades científicas.

El antioqueño, en su condición de informante, le fue detallando en su correspondencia las personalidades científicas y académicas del Virreinato de la Nueva Granada. Además, le solicitó que le dedicara a estas personalidades algunas de las plantas, porque habían sido "propagadoras de la botánica en ese territorio y perseguidos por el obscurantismo, que también hostigó a Mutis.

El botánico más notable que reseña Zea es a Eloy Valenzuela (1756-1734). Mutis llego a llamar a Valenzuela el Newton americano por haber dictado una sobresaliente cátedra de matemáticas ${ }^{22}$ en el Colegio del Rosario. En palabras de Zea, "Valenzuela era discípulo de Mutis y el primer compañero de su Expedición, agregando que en la flora de Bogotá hay muchos descubrimientos suyos y que el Sr. Mutis le había dedicado un precioso género» ${ }^{23}$.

Para Tomás Quixano y José Félix de Restrepo, solicita que se honre sus nombres con alguna planta. En estos casos, no porque fueran grandes botánicos, sino porque eran los precursores de la enseñanza de esta ciencia en Popayán. Considera Zea que si Cavanilles los menciona en alguna de sus

\footnotetext{
20 ZEA, F. A. (1791). "Avisos de Hebephilo... o discurso previo a la juventud», en Papel periódico de la ciudad de Santa Fe de Bogotá. Bogotá, números 8 y 9 de abril de 1791.

21 Cavanilles, en el caso del caucho, daba las dimensiones y en el Huaco exponía el nuevo género con las descripciones que le había realizado Zea. Anales de Historia Natural. Madrid, Imprenta Real, junio de 1800, pp. 111 y 125, febrero de 1801, p. 116.

${ }^{22}$ Carta de Zea a Cavanilles, Cádiz, 4 de febrero de 1799 . Carta n. ${ }^{\circ} 11$.

${ }^{23}$ Comentaba Zea que Valenzuela estaba escribiendo la «historia de los Juncos dibujando él mismo las láminas de tan hermosas plantas». Ibidem., Carta n. ${ }^{\circ} 11$.
} 


\section{CAVANILLES Y ZEA: UNA AMISTAD POLITICO-CIENTIFICA}

obras ayudará a que se propague con rapidez esta ciencia en el Virreinato donde «estos hombres se han atrevido a ser el objeto de la persecución de la ignorancia por inspirar á la juventud afición á la naturaleza ${ }^{24}$. Tampoco dejó de mencionar a su amigo Salvador Rizo, pintor de la Expedición Botánica, quien le hacía llegar plantas de Santa Fe y le había prometido enviarlas también a Cavanilles ${ }^{25}$.

En este contexto de la relación que se había establecido entre Zea y Cavanilles, resultaba evidente que el criollo le realizaría una minuciosa descripción de los trabajos que Mutis venía llevando a cabo para la publicación de la Flora de Bogotá ${ }^{26}$.

Lo primero que destaca el antioqueño de la Flora de Santa Fe es su gran. extensión, que alcanzaba a los 40 volúmenes con más de seis mil láminas en negro y en color. Como aspecto curioso comenta que los colores con los cuales se han dibujado las láminas son tomados de las mismas plantas. Además, le explicaba que Mutis venía trabajando en un curso de botánica americana para el Jardín de Santafé.

Otra obra que reseña Zea es la Quinología de Bogotá en la cual, según Mutis, había invertido 37 años de observaciones. La obra contenía dos partes: la primera, se refería a la descripción de siete especies de Chinchona; la segunda, a la parte medica.

En general, señalaba que la obra de Mutis era la más completa debido a que comprendía observaciones sobre toda la naturaleza americana. Se incluían láminas y descripciones de aves, insectos, cuadrúpedos, mareas atmosféricas, teorías sobre la formación de los montes y ríos, minerales, el movimiento de la tierra, agricultura del país, exportaciones de sus frutos, caminos que deberían abrirse, fomento de la población, enfermedades del Reino.

Zea, seguro de su pronta libertad, no dudo en regresar inmediatamente a su país para vincularse al trabajo de la Real Expedición Botánica al lado de su profesor y protector José Celestino Mutis, quien en carta a Cavanilles afir-

\footnotetext{
24 Posteriormente, el 26 de agosto del mismo año, recomienda a Sinforoso Mutis, quien según Zea tiene talento pero es indisciplinado y le vuelve a recordar los nombre de Félix de Restrepo y de Tomás Quixano: Dice: «Quanto me complacería las Restrepea y Quixana que Vm. me tiene prometido para dos hombres de mérito». Cádiz, 26 de abril de 1799; Cádiz, 26 de septiembre de 1799. Cartas n..$^{\circ} 15$ y 17.

${ }^{25}$ Zea y Rizo mantenían amistad desde la época en que el criollo ocupó la sub-dirección de la expedición Botánica. Posteriormente fue su interlocutor más directo para el envío de plantas a Europa. Cádiz, 11 de noviembre de 1798. Zea le comentaba a Cavanilles: "A él he hecho el encargo de las plantas que Vm. quiere y algunas otras». Cádiz, 4 de diciembre de 1798. Carta n. ${ }^{\circ} 8$.

${ }^{26}$ Le señala Mutis a Zea: «Tengo muchas especies, y conviene reservar la noticia para que no se adelante la Señora Flora Peruana á anticiparlo con alguna otra especie». Cádiz, 2 de enero de 1800 . Carta n. ${ }^{\circ} 18$.
} 


\section{DIANA SOTO ARANGO}

ma la inocencia de Zea y le da las gracias por el apoyo que le ha prestado a José María Cabal y a su sobrino Sinforoso Mutis ${ }^{27}$.

Ante el inminente regreso a Santa $\mathrm{Fe}$, Zea le garantiza a Cavanilles que viajará para conocerle, asegurándole que podía confiar en él para el envío de las plantas americanas. Al respecto le señala que: «Puede ser que Vm. no pierda del todo su trabajo, y que si logro volver a mi país, al que Mutis llama la capital de la Flora, tenga Vm. un corresponsal formado de su mano, que seguramente se esmerará en manifestar su reconocimiento". Zea lo tenía todo planificado para el envío de su mercancía. En Cartagena de Indias era amigo del administrador de las Aduanas y a Cádiz le haría llegar los cajones por intermedio del Sr. Francisco Nueve Iglesias quien, a su vez, se encargaría de hacerle llegar todos los encargos que fueran para él a América ${ }^{28}$.

Pero, también, le promete el envío de plantas del Perú, donde tiene un amigo que se las mandará a cambio de papel y el pago de los costes del transporte ${ }^{29}$.

El 21 de julio de 1799 se expide la Real Orden que declara la libertad de Zea, con derecho a la restitución en sus estudios y profesión ${ }^{30}$. Una vez obtenida la resolución de libertad, el criollo inicia de inmediato su reclamación por los salarios que dejó de percibir como Segundo Agregado de la Expedición Botánica de Santa Fe. Esta reclamación duraría hasta 1805, cuando se aclaró el tiempo que se le debería pagar ${ }^{31}$.

$\mathrm{Al}$ obtener su libertad se da a la tarea de organizar su viaje de regreso, dejando previamente organizados sus contactos en la metrópoli. Pero, una vez más, Mutis le marcaría su derrotero académico al ofrecerle que le costearía sus estudios por dos años en Madrid, al lado de su amigo Cavanilles ${ }^{32}$.

\footnotetext{
27 Carta de Mutis a Cavanilles, Santa Fe, 19 de agosto de 1802. Archivo de Cavanilles, Carpeta 3, Leg. 45.

${ }^{28}$ Cádiz, agosto 16 de 1799. Carta n. ${ }^{\circ} 16$.

29 Dice Zea que su amigo «tiene intima amistad con muchos misioneros de los que más han penetrado en aquella inmensa montaña, y están continuamente navegando el Marañón». Carta n. ${ }^{\circ} 16$.

30 Oficio de Mariano Luis Urquijo a Joséf Antonio Caballero, Aranjuez, 10 de julio de 1800. En este oficio se señala que a Francisco Antonio Zea, "de quien trata el oficio de V. E. de 31 de mayo último, fue remitido en partida de registro a estos Reinos por la Audiencia de Santafé, no tanto por lo que resultaba contra él en la causa sobre supuesta sublevación de Santafé, como, porque, siendo muy hábil y travieso creyó la Audiencia no convenía su residencia allí». Archivo General de Indias (AGI), Secretaría de Cámara, Legajo 158. Pombo a su vez le comenta en carta a Mutis que "celebra el acto de justicia de nuestro gobierno con Zea y su sobrino Sinforoso. 10 de diciembre de 1800, Cartagena». A. J. B. leg. 4758.

31 El período de tiempo era desde 1795 hasta el 13 de enero de 1803 . Aunque desde mayo de 1804 se ha había dado la orden al Virrey de Nueva Granada para que se le abonarán los citados salarios a Zea. Archivo General de Indias, Secretaría de Cámara, Legajo 158.

32 Carta de Mutis a Zea de finales de 1799. Véase carta de Zea a Cavanilles, 2 de enero de 1800. Carta n. ${ }^{\circ} 18$.
} 


\section{La Corneja desplumará a Ortega y a los peruanos}

Zea al iniciar su relación epistolar con Cavanilles dejó entrever el vasto conocimiento práctico que tenía de las plantas americanas. Por lo tanto, se atreve a criticar no solo la obra del Prodromo, sino también a realizar descripciones detalladas como la de la Hiraca, la Polygala Senega y el Guaco, entre otras ${ }^{33}$.

Parece que las diferencias entre Ortega y Cavanilles databan de 1784. En esta fecha, Cavanilles le manifestaba a José Viera y Clavijo (1731-1813) sus reservas sobre el botánico Ortega del que «jamás ha tenido grandes esperanzas" ${ }^{34}$. Pero la polémica pública comenzó con una carta anónima publicada en el Memorial Literario Instructivo y Curioso de la Villa y Corte de Madrid, en septiembre de 1788. "El autor de la carta atacaba a Cavanilles por crear demasiados géneros nuevos". Ademas, porque era un botánico de gabinete y que se había alejado de las tesis de Linneo.

Cavanilles regresa a España, en 1790, con la intención de tomar la dirección del Real Jardín Botánico de Madrid, según se lo había prometido el Intendente José Pérez Caballero. Pero la realidad fue diferente porque Ortega y su grupo se opusieron abiertamente a Cavanilles. Este le comentó a Mutis que, cuando lo quisieron hacer director del Jardín, «Ortega comenzó a esparcir voces contra mis obras y publicando dos anónimos para desacreditarlas y hasta llegó a ganar a nuestro amigo Zenón" ${ }^{35}$.

Cavanilles, por su parte, atacó públicamente el Prodromo de los expedicionarios peruanos y ellos, a su vez, en la publicación de la Florae Peruvianae et Chilensis Prodomus, publicada en 1794, rechazaban los numerosos géneros de Cavanilles. Esta obra de Ruiz y Pavón tuvo como objetivo presentar 136 géneros nuevos y establecer prioridad de las descripciones de primera mano frente a las publicadas de Cavanilles sobre la base de ejemplares desecados o datos de segunda mano» ${ }^{36}$. Cavanilles contestó estas críticas en su tercer volu-

\footnotetext{
${ }^{33}$ Dice Zea en relación al Guaco que como "carece de sus apuntes y herbario, no podré dar una descripción exacta y completa de las plantas, pero diré lo bastante para que un botánico no la desconozca.... Dejando a Mutis, como descubridor, intacto en derecho de dar nombre botánico a la planta, me contentaré con manifestar que es de género nuevo". Carta de Zea a Cavanilles, Cádiz, 30 de julio de 1798. En la carta del día 23 de enero de 1799 Zea le realiza una descripción detallada, en latín, de esta planta del Guaco.

34 Igualmente le censura a Ortega que él «estimaba más al botánico que a la botánica». Pelayo, Francisco y GaRILlETI, Ricardo. (1992). «La formación y actividades botánicas de A. J. Cavanilles", en Asclepio, Madrid, vol. XLIV, fascículo 2, pp. 129-154.

35 Carta de Cavanilles a Mutis del 28 de abril de 1795». Hernández DE ALBA, G. (1983). Tomo III, pp. 203-204.

${ }^{36}$ La primera versión del Prodromus se edita en 1794 y la segunda ampliada se realiza en 1797 en Roma. Posteriormente, Ruiz y Pavón publicaron en cuatro tomos la Flora peruviana
} 
men de los Icones et descriptiones plantarum quae aut sponte in Hispaniae crescunt, aut in hortis hospitantur ${ }^{37}$. La controversia continuó al publicar Ruiz una versión ampliada del Prodromus en Roma.

Zea participó en esta polémica; inicialmente, a través de su correspondencia y luego públicamente con el artículo de las quinas. En relación a la primera versión del Prodromus argumentó las equivocaciones de los peruanos en las descripciones y clasificaciones de los géneros. Sin embargo, siguió con interés el trabajo de Pavón en el herbario y biblioteca de Cavanilles y la publicación del primer tomo de la Flora peruviana et chilensis. Para Zea existían diferencias entre Pavon y Ruiz según lo había podido constatar en las disertaciones que ambos habían realizado en la Academia de Medicina. Al primero le consideraba con cualidades científicas mientras de Ruiz conceptuaba que «era incapaz de escribir en su vida dos renglones con acierto».

También puso al descubierto las intrigas de Ortega contra Cavanilles cuando le comenta que: "No se me ocultan los manejos de Ortega para incomodar a Vm. Hace casi dos años que un pedante, que a primera vista me deslumbró, estuvo importunándome para que le diese por escrito noticias de los yerros que Vm. hubiese cometido en sus descripciones de las plantas que yo conocía» ${ }^{38}$.

La controversia en el fondo radicaba en quién obtenía el mayor prestigio en la comunidad científica de los botánicos europeos, con el aporte de nuevas especies y géneros botánicos. Zea había tomado partido desde Nueva Granada por Cavanilles y así se lo hacía saber a su amigo botánico que en diferentes ocasiones había comentado con su maestro Mutis "las claras y acertadas descripciones de Cavanilles» 39 .

En este contexto anima a Cavanilles para que publique la segunda parte de la Corneja sin plumas ${ }^{40}$ que desenmascararía los plagios de Ortega. Esta obra, parece que correspondería a la continuación de la Colección de papeles sobre controversias botánicas que publicó Cavanilles en 1796. Esta segunda parte tenía la característica de ser un escrito de divulgación científica y por lo tanto no iba dirigida a los botánicos a quienes consideraba Zea «que jamás

\footnotetext{
et chilensis entre 1798 a 1802 . Del quinto tomo sólo se editaron las láminas. También publicaron, en 1798, la obra Systema vegetabilium Florae peruvianae et chilenses.

37 Esta obra de los Icones se editó en seis volúmenes entre 1791 y 1801 . Incluye 712 especies, muchas de ellas nuevas, con láminas que elaboró el mismo Cavanilles.

${ }^{38}$ Carta de Zea a Cavanilles, Cádiz; 30 de julio de 1798, n. ${ }^{\circ} 2$.

${ }^{39}$ Carta de Zea a Cavanilles, Cádiz, 20 de junio de 1798, n. $^{\circ} 1$.

${ }^{40}$ La Corneja tenía como objeto desprestigiar cientificamente a Ortega; demostrar sus errores en las descripciones botánicas; el incorrecto método que utilizaba en el curso de botánica que impartía en el Real Jardín Botánico de Madrid y poner en evidencia los daños que sufría el país al ocupar los principales cargos botánicos el señor Ortega.
} 


\section{CAVANILLES Y ZEA: UNA AMISTAD POLITICO-CIENTIFICA}

podría deslumbrar», y por lo tanto le parecía necesario hacerlo en términos "que todo el mundo entienda y juzgue la causa» ${ }^{41}$.

Zea se muestra dispuesto a realizar el escrito de la Corneja pero le expone a su amigo que debe hacerlo él para: «asegurar el golpe, y disipar de una vez este fantasma ${ }^{42}$. Finalmente, Zea se encargó de escribir la Corneja, que comentó asiduamente en casi todas sus cartas.

El criollo, en el transcurso de las cartas, va realizando comentarios concretos sobre la Corneja. Expone que: «Siempre había determinado quitar á la Corneja las plumas sin la carne; pero por más cuidado que ponga, ha de sentirlo ese hombre presuntuoso. Procuraré hacerlo de modo que él no pueda quejarse, ni el público dexar de abrir los.ojos».

Las cartas de Zea no tienen la retórica de la época. Por el contrario, se caracterizan por su nitidez y por las certeras burlas, irreverentes, que ponían en tela de juicio la formación botánica de Ortega. Consideraba que Ortega era un hombre que quería parecer lo que no era, porque: «no ha querido estudiar para ser botánico, ó más bien, no lo hizo Dios para ello, y de hecho lo quiere parecer. Demasiado tiempo nos ha tenido en este error, y aunque su Delectus Fl. Hisp. habrá desengañado a muchos como a mí, es justo que se disipe enteramente la ilusión» ${ }^{43}$.

El antioqueño, cumpliendo con lo encomendado por Cavanilles, incluye en la Corneja el análisis del curso de botánica que impartía Ortega en el Real Jardín Botánico de Madrid. Para este análisis, se apoya en los conceptos que le había dado Mutis sobre este curso al considerarlo «un monumento de vergüenza» ${ }^{44}$.

Zea diseñó para el estudio del curso de Ortega un esquema que comprendía los planes gubernamentales de apoyo a la investigación y fomento del estudio de esta ciencia y, por otra parte, pretendía demostrar los daños que sufría la botánica al tener un profesor tan inepto como Ortega.

El plan incluía establecer un paralelo entre lo que haría un profesor ilustrado y lo que estaba realizando Ortega en el Real Jardín Botánico de Madrid. Finaliza el plan puntualizando el atraso que experimentaba esta enseñanza por estar a cargo del señor Ortega que, por lo tanto, se debería disipar la ilusión de este nombre «funesto a la Botánica española».

Zea, a medida que avanza en el examen del curso de Casimiro Gómez Ortega $^{45}$, va planteando sus inquietudes porque no conocía todas las plantas,

\footnotetext{
41 Carta de Zea a Cavanilles, Cádiz, 5 de octubre de 1978, n. 5 .

${ }^{42}$ Carta de Zea a Cavanilles, Cádiz, 28 de agosto de 1798, n. ${ }^{\circ} 3$.

${ }^{43}$ Carta de Zea a Cavanilles, n. ${ }^{\circ} 3$.

${ }^{44}$ Carta de Zea de Cavanilles, Cádiz, 14 de septiembre de 1798, n. $^{\circ} 4$.

45 Gómez OrTega, C. y Palau, A. (1785-1795). Curso elemental de botánica teórico-práctica. Madrid, Imprenta Real, $1 .^{2}$ edición en 1.785 y la 2. ${ }^{a}$ en Madrid, Vda. e hijo de Marín, 1795.
} 


\section{DIANA SOTO ARANGO}

bibliografía y nombres de botánicos que se señalaban en el citado curso. Es curioso, pero Zea comienza a modificar su análisis a medida que va profundizando en el estudio del curso de Ortega que coincide con los comentarios que le envía Mutis, a finales de 1798, sobre la finalización de la polémica. Es posible que este cambio se deba al condicionamiento, que hacia Zea, de sus escritos a la realidad política del momento. $\mathrm{O}$, sencillamente temió que Ortega perjudicara sus relaciones "con los establecimientos botánicos" que él había entrado en contacto para sus proyectos americanos.

El hecho es que, con un mes de diferencia, cambia su lenguaje radical y despectivo, a uno más moderado. En un comienzo consideraba que la obra no creía que le sirviera ni a las artes ni al comercio ${ }^{46}$; e, irónicamente, no deja de señalar que: «Deseo engañarme en mi concepto, no solo por el bien de la ciencia, sino también por el honor de la Nación, en cuya gloria botánica me intereso mucho" ${ }^{47}$.

Una vez que Zea termina el análisis de la obra de Ortega, admite ante Cavanilles que debido al desprecio que sentía por este botánico no le había leido con atención y que ahora no puede decir que el autor sea tan irracional aunque la obra sea detestable ${ }^{48}$. En su análisis continúa señalando las descripciones incorrectas ${ }^{49}$ y manifiesta sus dudas sobre la importancia botánica que podía tener Ortega.

También resultaba evidente el cambio de Zea en relación al análisis de la Flora Peruana. Primero, en relación a la primera publicación del Prodromus, había manifestado que no sabían describir las plantas ni en el propio suelo ${ }^{50}$, y ahora aceptaba que los caracteres habían sido bien escogidos y toda la obra había sido escrita por un maestro. Centró su crítica en demostrar el poco rigor científico de la expedición peruana, indicando la poca extensión y las escasas descripciones de plantas para la flora de «tan vasto imperio», siendo

\footnotetext{
46 Señalaba Zea: «Sentiré mucho que la obra no corresponda, como me lo temo con fundamento, á los gastos que se han hecho y á la idea que nos han hecho concebir de las utilidades que reportarán las Artes y el Comercio» Carta de Zea a Cavanilles, $\mathbf{n} .^{\circ} 1$.

47 Carta de Zea a Cavanilles, n. ${ }^{\circ} 1$.

${ }^{48}$ Decía Zea: «Cosas prodigiosas he encontrado en el curso de Ortega. A la verdad jamas había leído dos páginas con atención, por lo mismo que le miraba con desprecio, como que esta fue mi primera lección de Botánica. No juzgo tan irracional al autor que á vista de las razones tan convincentes con que le arguyo, dexe de confesar que su obra es detestable». Carta de Zea a Cavanilles, Cádiz, 12 de octubre de $1798, \mathrm{n}^{\circ} 6$.

49 Por ejemplo, la que da sobre el arroz, Carta de Zea a Cavanilles, Cádiz, 14 de noviembre de 1798, n. $^{\circ} 7$.

${ }^{50} \mathrm{Su}$ ataque es demoledor contra Ruiz al comentar que ni siquiera sabe describir las plantas en su propio suelo. Dice: «Ruiz que tanto ha declamado contra las descripciones hechas por plantas secas ó degeneradas en los jardines i que dirá quando se les haga ver que él mismo las describe degeneradas en su propio suelo?»
} 


\section{CAVANILLES Y ZEA: UNA AMISTAD POLITICO-CIENTIFICA}

"muchas de ellas comunes que bastaba con nombrarlas» ${ }^{51}$. Es más, su informante peruano le había comentado que uellos no se atrevieron a entrar a la montaña y que solo recorrieron lo más poblado del Reyno» ${ }^{52}$.

A pesar de la diplomacia que caracterizó a Zea en el ataque público de sus oponentes, en este caso no demuestra miedo al enfrentamiento con Ruiz y Pavón porque: «ellos habían declarado la guerra y él abriría la campaña» ${ }^{53}$. Además, no podía permitir que quedaran en el ambiente académico y comercial las afirmaciones de la Flora Peruana sobre «la quina de Santa Fe» y que se desconociera el descubrimiento de Mutis sobre las variedades de esta planta. Estas afirmaciones afectaban el honor de su maestro y el comercio de la quina santafereña en Europa.

Finalmente, Zea terminó la Corneja, en noviembre de 1798, y le comentó a su protector que lo único que le faltaba era «corregir el estilo y pasarla a limpio». Después de la fecha señalada prometía continuamente el envío de la obra y pasado un año, cuando iba a partir para Madrid, se disculpa por haber suspendido la copia de la Corneja por que en ese momento no podía chocar de frente con Ortega. El miedo seguramente, radicaba en el perjuicio que le podía hacer Ortega con los establecimientos botánicos que posiblemente le apoyarían en su plan de la Expedición Botánica para Santa Fe de Bogotá ${ }^{54}$. Sin embargo, le avanza a Cavanilles que el curso elemental de Ortega es: "absurdo en el plan, inconexo en las ideas, difuso en lo que no importa, falso en lo más necesario, acribado de errores y casi enteramente compuesto de exemplos sin doctrinas, con tantas estrellas que parecen constelaciones ${ }^{55}$.

Si bien es cierto que Zea no publicó la Corneja, sin embargo, en el escrito de las quinas y ya en París, utilizó la intriga y su pluma en la defensa de la obra científica de Cavanilles y de su maestro Mutis.

\section{Zea llega de estudiante a París y regresa a España con reconocido prestigio de difusor de la botánica}

El criollo no llegó a imaginarse que aquella tímida carta que le envió a Cavanilles en el mes de junio de 1798 le iba a cambiar su vida y destino en Europa.

Cuando tenía ya todo organizado para el tan anhelado regreso a la patria le llega una carta de Mutis para costearle a él y a su sobrino Sinforoso los

\footnotetext{
51 Carta de Zea a Cavanilles, Cádiz, 26 de abril de 1799, n. ${ }^{\circ} 14$.

52 Carta de Zea a Cavanilles, Cádiz, agosto de 1799, n. ${ }^{\circ} 16$.

${ }^{53}$ Carta de Zea a Cavanilles, Cádiz, 2 de enero de $1800, n .^{\circ} 18$

${ }^{54}$ Carta de Zea a Cavanilles, $n .^{\circ} 18$.

55 Carta de Zea a Cavanilles, n. $^{\circ} 18$.
} 
estudios de botánica, durante dos años, en Madrid «aprendiendo al lado de Cavanilles ${ }^{56}$.

Para Zea los dos años de estudio que le proponían eran demasiado tiempo. Sin embargo, complacería a su maestro y se detendría en Madrid el tiempo justo para «llenar sus principales ideas». Pero su protector Cavanilles, luego de tenerlo casi un año en Madrid, lo convenció y le consiguió una comisión para que continuara sus estudios en París. Cavanilles así se lo manifiesta en carta a Mutis, cuando le dice que: «también traté a la larga a su discípulo Zea, contribuí a que le destinasen a París para que se perfeccionase» ${ }^{57}$.

El antioqueño partió a París con una Real Comisión que le otorgó la Secretaría de Estado para «recoger algunos libros e instrumentos, y de instruirse en el último estado de las ciencias naturales». Esta comisión no incluyó soporte económico ${ }^{58}$ : el apoyo lo recibió de su maestro José Celestino Mutis ${ }^{59}$.

Mutis financió a Zea y a su sobrino Sinforoso en sus estudios de Madrid y París, desde 1800 a 1802 . El medio que utilizó Mutis fue el de la quina. Cuando Zea viajó a París llevó consigo un gran cargamento de quina para vender en Francia.

A través de José Ignacio Pombo ${ }^{60}$, José Celestino Mutis enviaba la quina a la ciudad de Cádiz. Una parte del valor de estos cargamentos era para sostenimiento de los dos criollos y el resto para la compra de libros e instrumentos que solicitaba Mutis.

Siendo la quina el principal medio de financiación, esta planta se convirtió en una de las inquietudes centrales del criollo en París. Para él era prioritario que se reconociera la eficacia medicinal de la quina de Santa Fe, en relación a la peruana ${ }^{61}$. En este sentido se debe entender su preocupación por demostrar en Francia la mayor eficacia curativa de la quina santafereña en relación con la peruana. Para demostrar sus afirmaciones mandó realizar

\footnotetext{
56 Carta de Zea a Cavanilles, $n .^{\circ} 18$.

57 Cavanilles lo comenta a Mutis en carta del 18 de agosto de 1801, n. ${ }^{\circ} 26$. Madrid. HeRnÁNDEZ DE Alba, G. (1983). Tomo III, p. 210.

58 Oficio del Ministerio de Estado del 8 de abril de 1805 donde consta que Zea no percibió ningún sueldo durante su estancia en París de 1801 a 1802. Archivo General de Indias, Secretaría de Cámara, Legajo 158.

${ }^{59}$ Mutis inicialmente le propone a Zea costearle sus estudios con Sinforoso Mutis en el Real Jardín Botánico de Madrid al lado de Cavanilles. Carta n. ${ }^{\circ} 18$.

${ }^{60}$ Relación de cartas de Pombo a Mutis sobre el envío de quina a Zea: Cartagena, 10 de junio de 1800,10 de diciembre de 1800,2 de mayo de 1802, 20 de noviembre de 1802 .

${ }^{61}$ En este escrito sobre la quina señala: «creyendo que la química es quien nos puede suministrar las luces necesarias en tan importante materia, he solicitado que se hagan los análisis de todas quatro especies por algunos de los químicos más célebres de Europa». Doc. cit., p. 22.
} 
experimentos y no descansó hasta que el Instituto Nacional de Francia declaró "las virtudes curativas de la quina Santafereña» ${ }^{62}$. Además, gestionó la posibilidad de publicar el libro de las quinas de Mutis en París ${ }^{63}$.

Recordemos que, antes de su viaje a París, había publicado un controvertido artículo sobre la quina en los Anales de Historia Natural ${ }^{64}$. Zea en esta ocasión reivindicó para su maestro Mutis la gloria de ser el descubridor de las cualidades medicinales de este árbol. Señalaba que: «siete son las especies legítimas de Chinchona descubiertas por el Sr. Mutis (son las únicas que hasta ahora se conocen en Santa Fe, pues las que se dicen descubiertas por D. Sebastián López son las mismas oficiales por el sr. Mutis)... A los trabajos felices del Sr. Mutis debemos el descubrimiento de sus eminentes virtudes, confirmadas por el Sr. Lambert ${ }^{65}$. Por supuesto no deja de referirse a los conceptos de Ruiz y de Pavón y por lo tanto manifiesta que: «le es indispensable indicar sus equivocaciones, porque llevan la recomendación de observaciones hechas en el suelo nativo de la quina por botánicos distinguidos por su carácter público» ${ }^{66}$. El escrito de Zea es comentado por Cavanilles quien le expone a Mutis que su discípulo realizó una excelente defensa de su maestro y de las quinas ${ }^{67}$.

Cavanilles toma partido públicamente por el artículo de Zea sobre las quinas y pone de manifiesto que los expedicionarios Ruiz y Pavón trabajaban bajo las órdenes del Sr. Ortega para refutar la memoria del Sr. Zea ${ }^{68}$. Es más, espera que «el sabio Mutis y su discípulo Zea respondan con la moderación que brilla en sus escritos» ${ }^{69}$, como también lo harán Vahl, Jussieu y otros científicos europeos.

\footnotetext{
62 Véase cartas de Zea a Cavanilles de París, 4 de abril, 8 de mayo y 1 de julio de 1801: corresponden a los números, 22, 23, 25.

${ }^{63}$ Carta n. $^{\circ} 22$.

${ }^{64}$ Zea se encontraba en Madrid en febrero de 1800. Posiblemente escribe este artículo de las quinas entre Cádiz y Madrid. En septiembre se publica el polémico artículo sobre "Memorias sobre la quina, según los principios del señor. Mutis», por D. Francisco Antonio Zea, botánico de la Expedición de Santa Fe, y discípulo del mismo Sr. Mutis, Director de ella", en Anales de Historia Natural, n. ${ }^{\circ}$ 5, T. II, Madrid, en la Imprenta Real, septiembre de 1800. pp. 196 a 235. Publicadas en Fernández PÉREZ, Joaquín (1993): (Estudio preliminar y edición) Anales de Historia Natural. 1799-1804. Madrid, Ediciones Doce Calles, y (1954) Flora de la Real Expedición... Tomo IV. Madrid, pp. 98-103.

${ }^{65}$ Ibidem., pp. 202-205.

66 Ibidem., p. 230.

${ }^{67}$ Carta de Cavanilles a Mutis donde le comenta que: «Nuestro Zea, su más ferviente admirador apasionado, me dio datos para dar algunas pinceladas. Este joven defendió a vuesamerced contra estos zolios, enemigos de los estudiosos, y publicó una excelente disertación sobre la quina». Madrid, 19 de junio de 1802. HernándeZ de AlBA, G. (1983). Tomo III, p. 213.

68 Ibidem., Tomo IV, n. ${ }^{\circ} 10$, junio de 1801. p. 110.

${ }^{69}$ Ibidem., p. 116.
} 


\section{DIANA SOTO ARANGO}

La polémica sobre la quina, según comenta Zea, se daba en toda Europa. En el Instituto se hicieron las pruebas ${ }^{70}$ además de las que él realizó con la colaboración de Cels y el apoyo de su profesor Ventemant. Era consciente de que la campaña que él estaba realizando a favor de la quina santafereña, en un momento llegó a equipararse a las «intrigas» ya conocidas de Ortega ${ }^{71}$. Finalmente, varios científicos franceses se pronunciaron a favor de la eficacia curativa de la quina de Santa Fe. Por ejemplo, la obra de Alibert adopta la doctrina de Mutis y da el crédito a la quina de Santa $\mathrm{Fe}^{72}$. Igualmente, le informa Zea a Cavanilles que el director de la Escuela médica va a publicar una obra donde adopta la doctrina de Mutis y el Sr. Vahl, en su obra, también dará a conocer su informe sobre los análisis de la quina.

Con el veredicto de los profesores del Instituto Nacional de Francia sobre la quina de Santa $\mathrm{Fe}$, Zea logró, por una parte, prestigio para su maestro Mutis y, por otra, garantizó el comercio de la quina santafereña en Europa. En tales circunstancias, logró vender a buen precio las más de 60 cargas de quina que Mutis le había enviado para su sostenimiento y para la compra de libros y del laboratorio de química que tanto anheló el sabio gaditano para Santa $\mathrm{Fe}^{73}$.

La polémica sobre la quina y el viaje de Zea a Francia se comentaba igualmente en los círculos botánicos del Virreinato. Pombo la seguía con interés y le comentaba a Mutis: "Lo que he visto en ese miserable papel publicado en Madrid, de ese don Sebastián López, contra vuesamerced, Zea y Rieux en respuesta a la memoria de aquél sobre la quina ${ }^{74}$. Zea en el articulo de las quinas, establece una especial clasificación sobre las variedades de esta planta que habían publicado los peruanos. Este hecho tampoco pasa inadvertido a Pombo, quien de inmediato se lo consultó al maestro Mutis ${ }^{75}$.

Aunque el criollo en este trabajo señala que para Mutis «las especulaciones mercantiles» no incidían en el gaditano por ser éste «un verdadero sabio»

70 Carta n. 22

71 Decía Zea: "dirá Vm. que me he vuelto tan intrigante como el sr. Ortega». Carta n. ${ }^{\circ} 23$.

72 Carta de Zea, n. 25.

73 Carta de Zea a Cavanilles, n. ${ }^{\circ}$ 25. Zea llevó personalmente la quina de Cádiz a París y la vendió en esta ciudad, según lo comentaría posteriormente Rizo en su oficio del 26 de julio de 1809 de Santa Fe.

74 «Carta de Pombo a Mutis donde le comenta la polémica que existe en España sobre la quina», 20 de junio 1803. A. J. B. III, 1,1, 254. "Carta de Pombo a Mutis donde le comenta la polémica de la quina. Resalta que Ruiz critica a Bompland. Cartagena, 10 de julio de 1801 ". En la carta del 3 de abril de 1802 se alegra del viaje de Zea a París. Hernández de AlBA, G. (1983). Tomo IV, p. 170.

75 "Carta de Pombo a Mutis donde le comenta el escrito de Zea sobre las quinas». Dice: "Como creo lo sea todavía Zea, quien en su memoria sobre las quinas redujo todas las de los peruanos a las cuatro especies de vuesamerced. Cartagena, 20 de enero de 1806". A. J. B. III, 1,1 . 


\section{CAVANILLES Y ZEA: UNA AMISTAD POLITICO-CIENTIFICA}

y no un "profesor mercenario", lo cierto es que en la realidad tanto para Mutis como para Zea era muy importante el hacer reconocer la superioridad de la quina santafereña sobre la peruana para garantizar el comercio de ésta en Europa. No hay duda de las cualidades comerciales de Zea quien demostró un amplio conocimiento sobre los valores mercantiles de la quina ${ }^{76}$.

Cuando Zea llega a París, en el mes de diciembre de 1800, lo primero que hace es ponerse en contacto con las personalidades académicas que le había recomendado Cavanilles. Así se lo manifiesta el criollo a Cavanilles cuando le comenta que: «los profesores a quienes $\mathrm{Vm}$. tuvo la bondad de recomendarme, me han recibido con todo el aprecio que Vm. sabe inspirar a los que le tratan ${ }^{77}$.

El rasgo más sobresaliente de Zea fue su poder de asimilación y adaptación a los círculos científicos y políticos. El hecho es que el primer grupo de contacto de Zea fue el de los antiguos amigos que Cavanilles había dejado durante su estancia en París. En especial se relaciona con Jacques Philippe Martin Cels (1740-1806) y Etiene Pierre Ventemant (1757-1808), quienes seguían siendo, según Zea, los más fieles amigos de Cavanilles ${ }^{78}$.

Cavanilles durante su estancia en París realizó sus prácticas botánicas en los Jardines de Aremberg de Cels. Por su parte, Ventemant publicó una obra sobre las plantas cultivadas en el Jardín de Cels que Cavanilles comentó en los Anales de Ciencias Naturales ${ }^{79}$ y ampliamente difundido en el Magazin Encyclopédique ou Journal des sciences, des lettres et des arts de París ${ }^{80}$.

Para Zea era Ventemant el botánico del «que se podría esperar más». Ventemant se había interesado en la obra de Cavanilles para publicarla en Ale-

76 Por ejemplo señala el bajo precio al que se compraba la quina en Cádiz y los altos valores que adquiría una vez que se trasladaba el producto a centro Europa. En el escrito citado sobre las quinas señala: "Lo cierto es que no todos los cajones se averiaron, pues comprados en Cádiz a vil precio, se vendieron después con estimación en Italia, Inglaterra y Holanda». Ibidem., p. 221.

77 Comenta Zea que le han dado todos los medios y que agradecen las plantas que les envió Cavanilles. Carta de Zea a Cavanilles, París, 29 de diciembre de 1800. Carta n. ${ }^{\circ} 20$.

78 París, 30 de agosto de 1801 . Carta n. $^{\circ} 26$.

79 Por Real orden se creó en 1799 los Anales de Historia Natural que luego se denominó Anales de Ciencias Naturales. Cavanilles participó en la fundación de esta revista junto con Cristiano Herregen, Luis Proust y Domingo Fernández. Esta publicación dejó de editarse a la muerte de Cavanilles. Ventemant (1757-1808) publicó Description des plantes nouvelles et peu connus cultivés dans le jardin de J. M. Cels. LÓPEZ PIÑERo, J. M. y otros. (1983), Diccionario histórico de la Ciencia Moderna en España. Madrid, Ediciones Península, p. 201.

${ }^{80}$ Se señala la noticia de la descripción de nuevas plantas cultivadas dentro del Jardín de J. M. Cels, con figuras por E. P. Ventemant del Institut National de France. Se consultó en la Biblioteca Nacional de París en la Colección completa del Magasin Encyclopédique. Rédigée por J. B. Sajou, 1819. Tomos 37, año 1801, pp. 86-92. Tomo 38, año 1801, pp. 98 a 102. Tomo 43, año 1802, p. 48. 


\section{DIANA SOTO ARANGO}

mania ${ }^{81}$ y había tomado partido por él en su polémica con Ortega. Así lo exponía Zea al señalar que Ventemant «publicará una planta mal descrita por Ortega». La confianza con Ventemant es tal que, al final de su estancia en París, Zea le solicita a Cavanilles que le escriba «bajo cubierta de Ventemant». La realidad era que Zea se había convertido en la persona de confianza del científico a quien, al no hablar el español, el criollo le hacia las funciones de traductor. Este hecho se lo pone de manifiesto Zea a Cavanilles cuando le comenta: «Me alegro que la dificultad del idioma no permita a Ventemant encargarse del anuncio, porque lo retardarían sus ocupaciones. Ha condescendido que yo lo haga y corregidas las faltas del lenguaje, lo publique en su nombre» ${ }^{82}$.

En la capital francesa, Zea se relaciona igualmente con otros amigos de Cavanilles y con políticos americanos y españoles ${ }^{83}$. Entre otros con Antoine Laurent Jussieu (1747-1836), René Desfontaines (1750-1833), J. B. Lamarck (1744-1829) y con André Thouin (1747-1823). Con todos ellos establece una relación de intermediario de las plantas que les enviaba Cavanilles y poco a poco fue construyendo su imagen de experto en el conocimiento de las plantas americanas que tanto interesaban a los botánicos europeos. Además, realizó experiencias botánicas en el jardín de la casa del célebre químico Nicolás Louis Vauquelin (1763-1829) ${ }^{84}$. En general, Zea se vanagloriaba de tener amistad con los profesores más célebres de Europa.

Otro papel fundamental que realizó Zea en París fue el de divulgador de la obra de Cavanilles y de Mutis. Se convierte casi en agente editorial del primero. Entre otras gestiones editoriales contacta e identifica a un traductor de alemán y de italiano con el objeto de publicar «algunas memorias de Cavanilles en Berlín y otras en italiano» ${ }^{85}$. Luego contrata a su cargo un traductor que aunque considera que le «cuesta mucho dinero pero es superior a los dos

81 Decía Zea «Ventemant ha remitido a Alemania las descripciones de Vm. para que se publiquen». París, 8 de mayo de 1801 . París, 1 de julio de 1801 . Cartas $n{ }^{\circ} 23$ y 25 .

82 París, 14 de junio de 1802 . Carta n. ${ }^{\circ} 31$.

83 Zea en París establece amistad con los científicos y políticos de esta metrópoli. Frecuentaba la casa de Francisco Miranda, quien en ese momento era general del ejército de la Revolución francesa. Botero SALDARRIAGA, R. (1945), p. 67. Igualmente establece relación con el embajador de España en Francia que según Zea «desprecia a Ortega». Carta n. ${ }^{\circ} 20$.

84 Vauquelin trabajó en la Ecole Polytechnique hasta 1797. Fue profesor de la École de Mines hasta 1801. En 1799 publicó Manuel de l'essayeur. Fue el primer director de la École de Pharmacie en 1803. Descubrió dos nuevos elementos en sus numerosos análisis de minerales. Trabajó con Fourcroy en análisis de sustancias de vegetales y animales y a quien sucedió en la cátedra de química del Museo de Historia Natural. Staudinger, H. y Verone G. (1976). Dictionary of scientific biography. Vol. XIII, Nueva York, Charles Scriber s Sons. 1976, pp. 596597. París, 4 de febrero de 1801 , carta $n^{\circ} 21$.

${ }^{85}$ Carta n. ${ }^{\circ} 20$. 


\section{CAVANILLES Y ZEA: UNA AMISTAD POLITICO-CIENTIFICA}

anteriores debido a que es francés que sabe el español» ${ }^{86}$. Zea consideraba que una vez saliera el informe del Instituto sobre las quinas, podía publicar el trabajo de Mutis en francés ${ }^{87}$.

Es posible que su vinculación con Aubin Louis Millin (1759-1818), director del Magazin Encyclopedique ou Journal des sciences, des lettres et des arts ${ }^{88}$ de París, contribuyera a que Zea se aficionara a la labor periodística que luego iba a desarrollar como profesional en España. En el citado periódico colaboró con algunas noticias sobre las actividades botánicas de Cavanilles y Mutis. Además, insertó "una carta de contestación contra los señores peruanos» y se publicó una reseña sobre los botánicos españoles en donde él se incluía ${ }^{89}$.

Zea exponía que la mayor parte de los «diaristas» eran sus amigos y comentaba que a ellos no había más que avisar para «lo que se ofrezca». Por supuesto, el criollo garantizaba la publicidad de los escritos de Cavanilles así que esperaba la llegada del tomo n. ${ }^{\circ} 6$ de los Icones para realizar, según él, "un soberbio anuncio» ${ }^{90}$. En la controversia con Ortega era imprescindible dar a conocer las publicaciones de Cavanilles para contrarrestar la imagen de la obra de la Flora Peruana.

El articulo que se publica en el Monitor de Historia Natural de París, del 12 de septiembre de 1801, sobre el estado de las ciencias naturales de España, se reseña la actividad de los diferentes botánicos españoles. Se destaca el nombramiento de Cavanilles en la dirección del Real Jardín Botánico de Madrid y las transformaciones que estaba realizando en la institución con la colaboración del ministro de Estado, Pedro Cevallos.

86 Carta n. 22 .

87 Señala Zea que «si logro empeñar a un librero en la empresa, publicaré Quinología, suplemento y cuanto haya parecido por una y otra parte con notas como lo hizo Vm. y tal ves su misma colección de papeles, bien que por separado». Carta n. ${ }^{\circ} 22$

88 Millin publicó la obra Eléments d'historie naturelle. La tercera edición data de 1802. En el citado Magazin comenta Zea que publicaba permanente diferentes noticias. Nosotros hemos revisado esta publicación y no hemos localizado todas las informaciones que señalaba Zea en sus cartas. Zea comentaba a Cavanilles que «notifico a Vm. con esta relación todo esta se publicará en el Magazin como de costumbre». París 14 de junio de 1801. Carta n. 24.

89 En relación a Zea se le describía como: «disciple chéri de Mutis, est á present á París, óu il s`instuit auprés de Jussieu, Ventemant, etc. des nouvelles découvertes qui illustrent la science. Zea a publié quelques idées de son maitre sur les différentes especes de quinquina dans les annales des sciences naturelles de Madrid, et il travaille a présent á les confirmer par des expériences décisives». En este mismo articulo se daba noticia sobre Cavanilles, Mutis, Ortega, Ruiz y Pavón. Magazin Encyclopédique ou Journal des sciences, des lettres et des arts. París, año IX, 1801. T. 36, pp. 112 a 114.

90 Zea manifestaba que «las circunstancias hacen indispensable anunciar el tomo 6 de sus Icones de modo que haga una viva impresión». Cartas n. ${ }^{\circ} 24$ y 31. 
Igualmente, en ese mismo año se da conocer en el citado periódico que la Sociedad médica de París inscribió en su última sesión como miembros honorarios a don Zenón Alonso, Oficial primero de la Secretaría de Gracia y Justicia de Indias en Madrid; a don Antonio José Cavanilles, director del Real Jardín Botánico de la misma Corte, y a don José Celestino Mutis, botánico y astrónomo de S. M. y director de la Expedición Botánica en el Reyno de Santa Fe de Bogotá. Otro hecho que se resalta es la labor desarrollada por Castillo y Zea en la introducción de la vacuna en España.

En París, el criollo además de escribir en los Anales de Historia Natural de Madrid se convierte en el divulgador de esta publicación en la capital gala, que según Zea tenían gran acogida y por lo tanto lamentaba no haber «traido una docena de ejemplares ${ }^{91}$.

Aunque sólo estuvo dos años en París, no por esto dejó de aprovechar al máximo la experiencia académica que le ofreció Francia. Resultó evidente que amplió el circulo de amistades y recogió la práctica administrativa de las instituciones científicas que funcionaban en el país galo. En efecto, el criollo le demuestra a Cavanilles las ventajas de construir una estufa en el Jardín de Madrid de forma similar a la de París ${ }^{92}$. Igualmente, le propone que se organice en Madrid una casa de fieras y él se compromete a llevarle el diseño de la que se iba a construir en París. Pero lo que más deseaba Zea era la organización de un "gabinete de maderas, frutos, bálsamos, resinas", prometiéndole a Cavanilles que estaba dispuesto a cooperar en esta empresa ${ }^{93}$. El objetivo era situar en primer plano el Real Jardín Botánico de Madrid «convirtiéndolo en la capital de la Flora de Europa ${ }^{94}$.

El último período de su estancia en París lo dedica Zea a visitar gabinetes y escuelas y a solicitar de sus amistades libros e instrumentos que llevaría para Santa Fe. Finalmente, desde la capital francesa elabora en 1802 un plan para una nueva Expedición Botánica en Santa Fe de Bogotá ${ }^{95}$. Este proyecto lo venia concibiendo desde su estancia en Cádiz en 1799, cuando pensó dedicar una expedición a su tierra natal de la región antioqueña. El nuevo diseño lo estructuró bajo la dirección de Mutis porque en Santa Fe se le esperaba en el cargo de sub-director y continuaba siendo el sucesor de Mutis. El Plan era

91 París, 29 de diciembre de 1800 . Carta $n^{\circ} 20$.

92 Zea le comenta a Cavanilles que la estufa de París ha costado cincuenta mil escudos. París, 20 de octubre de 1801, carta n. $^{\circ} 28$.

${ }^{93}$ Carta n. $^{\circ} 28$.

94. Carta n. ${ }^{\circ} 31$.

95 «Luminoso plan reorgánico de la Real Expedición Botánica propuesto desde la ciudad de París por don Francisco Antonio Zea, miembro titular de la misma. 1802", en HernándeZ DE Alba, G. (1985). Documentos para la Historia de la educación en Colombia. Bogotá, Editorial Kelly, pp. 88-133. 
ambicioso y optimista y reflejaba la experiencia europea que aspiraba a desarrollar en el Virreinato.

\section{El criollo Zea director del Real Jardín Botánico de Madrid}

A partir de los conocimientos adquiridos en París, y por su estrecha relación con Cavanilles y con el grupo de los afrancesados del círculo de Godoy y de Pedro Cevallos, su carrera académica va en ascenso vertiginoso. Pero si bien es cierto que su deseo era regresar a su tierra natal ${ }^{96}$, siempre encontraba una negativa gubernamental a sus solicitudes de regreso, y por el contrario le ofrecían nuevas opciones que le obligaban a permanecer en Europa. En esta ocasión, su matrimonio con la gaditana Felipa Meilhon ${ }^{97}$ y el nombramiento de segundo profesor en la cátedra de botánica del Real Jardín y de segundo redactor de la Gaceta y el Mercurio de Madrid ${ }^{98}$, lo comprometían nuevamente a quedarse en la Metrópoli.

Ignacio Pombo ${ }^{99}$ y Cavanilles ${ }^{100}$ le comunican a Mutis que a Zea se le había nombrado segundo profesor en el Real Jardín Botánico de Madrid y que se había casado en Cádiz. Por su parte Mutis le responde a Cavanilles, el 9 de junio de 1803, manifestándole que se alegraba por el cargo que le habían otorgado a Zea como segundo profesor del Jardín Botánico pero no veía con agrado su cargo en El Mercurio y la Gaceta de Madrid por que le quitaría

96 El regreso a su tierra natal siempre estuvo en su mente y lo manifestó por escrito desde el mismo momento que salió en libertad en 1799, en la ciudad de Cádiz. Situación que vuelve a plantear nuevamente desde Cádiz en 1803, cuando regresa de París.

97 En Cádiz se casa en el invierno de 1803 con Felipa Melihon, hija de padres franceses, con quien tuvo dos hijas; una murió y la otra fue la vizcondesa de Rigny. Botero SALDARRIAGA, R. (1945), pp. 3-84.

98 Se le nombra Segundo profesor de botánica por oposición y Segundo redactor de La Gaceta y El Mercurio de Madrid, 13 de enero de 1803. El salario que se le asignó fue de 24. 000 reales de vellón al año. A.G.I., Sección Quinta, Audiencia de Santa Fe, legajo 667.

99 Carta de Pombo a Mutis donde le comenta que Zea ya no viajará a Nueva Granada porque le ha sido ofrecido un empleo en el Real Jardín Botánico de Madrid. 10 de junio de 1803 , Cartagena. A. J. B. III, 1,1, 253.

${ }_{100}$ Cavanilles le comenta a Mutis que se ha nombrado a Zea segundo profesor del Jardín Botánico y segundo redactor de El Mercurio y La Gaceta de Madrid y que Ortega ataca en sus escritos a Mutis; Zea, Cavanilles, Vahl, Ventenat, De Jussieu. Dice: «El empleo de Zea es el de segundo redactor del Mercurio y de la Gaceta, empleo de 21 mil reales a cuyo suelo se le han añadido tres mil con el título de segundo profesor. Es cierto que para desempeñar estos cargos será preciso el que trabaje mucho, la nueva obligación de casado, que acaba de contraer en Cádiz, le estimulará de nuevo". 22 de enero de 1803, Madrid. HeRnándeZ DE AlBA, G. (1983). Tomo III, pp. 214-215. 


\section{DIANA SOTO ARANGO}

tiempo para la botánica ${ }^{101}$. Pombo, que siempre comentaba con Mutis la actividad académica de Zea, en esta ocasión no deja de manifestar que su alumno tiene "más afición a la política que a la botánica» 102 .

El criollo quedó marcado en lo académico-político por su estancia en París. A su regreso a Madrid, ya como segundo profesor del Jardín Botánico y en especial como director de la Gazeta y El Mercurio de Madrid, refleja su tendencia francesa en las informaciones político-científico-académicas y en la reseña de libros ${ }^{103}$. En estos periódicos se informa a los lectores sobre las actividades del Instituto Nacional de Francia, donde había estado vinculado como alumno. En la reseña de las publicaciones repite el libro Historia natural de Buffon y menciona todas las acciones académicas y de publicaciones de su protector Cavanilles. Además, da a conocer cuanto libro aparece relacionado con el comercio y la agricultura. En general, podríamos decir que Zea deja marcada la redacción de la Gazeta de Madrid durante su dirección con las noticias científicas de tendencia francesa, una mayor descripción de los libros científicos, relación de nuevos métodos de enseñanza, creación de escuelas y actividades de las Sociedades Económicas de Amigos del País. En El Mercurio continúa la misma línea de pensamiento pero con mayor análisis en las informaciones políticas.

A Zea no se le puede acusar de no haber dado noticias sobre sus oponentes académicos. Por el contrario, Zea relaciona la obra de Hipólito Ruiz sobre la quina de 1792 pero sutilmente no deja de mencionar la quina anaranjada de Santa Fe que había descubierto Mutis con mayor efecto medici$\mathrm{nal}^{104}$.

En este contexto, desde sus primeras clases en el Real Jardín Botánico, señala a los estudiantes que «el encargo de su enseñanza es la de demostrar la utilidad de esta ciencia» ${ }^{105}$. Esta posición académica la reafirma en el discurso de apertura de curso que realiza en esta institución en 1805.

101 Carta de Mutis a Cavanilles, Santa Fe 9 de junio de 1803. Publicado en Hernándeż DE AlBA, G. (1983). Tomo II, pp. 200-201.

102 Carta de Pombo a Mutis, Cartagena, 20 de noviembre 1803. A. J. B. III, 1,1.

103 En el primer número de El Mercurio, de enero de 1803, en el apartado de "Política» elabora un artículo sobre "Idea del estado de la Europa en el año pasado de 1802». En este artículo elogia a Napoleón, lo trata como héroe. El Mercurio de España. Madrid, Tomo I, en la Imprenta Real, p. 7.

$104 \mathrm{Al}$ respecto señala: «Esta obrita que es continuación de aquella primera original en su clase, es sumamente importante a todos los hombres en general, y con especialidad a los profesores de medicina en sus tres ramos; comerciantes y drogueros...». La Gazeta de Madrid, martes 29 de marzo de 1803 .

105 «Borrador de un manuscrito de una clase de Zea en el Real Jardín Botánico de Madrid sobre lo que el denominó "El estudio de la Historia Natural y la botánica». Madrid, 1803. A.J.B. III, 7, 1, 10. fls. 1. 


\section{CAVANILLES Y ZEA: UNA AMISTAD POLITICO-CIENTIFICA}

Su designación para la dirección del Real Jardín Botánico ${ }^{106}$ de Madrid causó gran desconcierto y críticas que él mismo y Mutis comentarían en diferentes documentos. Porque no era en esa época común que un criollo y expresidiario ocupara la dirección de uno de los principales centro científicos de la Metrópoli. Pombo comenta positivamente el nombramiento de Zea por lo útil que podía ser a Mutis y a la Expedición de Santa $\mathrm{Fe}^{107}$.

Para entender el apoyo que recibió Zea en su nombramiento y en los proyectos que le aprobaron desde la dirección del Jardín Botánico, se debe analizar el circulo de afrancesados que se había formado en España alrededor del Principe de la Paz. A este grupo pertenecían Cavanilles, Zenón Alonso $^{108}$ y Pedro Cevallos ${ }^{109}$, Primer Secretario de Estado y cuñado de Godoy. Además, el antioqueño Zea no perdía oportunidad en sus escritos para valorar el pensamiento liberal y de progreso del Príncipe de la Paz ${ }^{110}$. Pensamiento que suponemos también compartía Pedro Cevallos, como lo demostró posteriormente al participar con el grupo de los afrancesados en la firma de la Constitución de Bayona. Zea desarrolló con Cevallos una extensa relación epistolar oficial y sus proyectos fueron tramitados por éste teniendo por respuesta manifestaciones de complacencia por parte de Godoy.

Sin perder de vista que en su empeño pudieron colaborar las dotes políticas que poseía Zea; su brillante carrera académica, avalada por Mutis; su aptitud para planificar; su capacidad oratoria y su talento para convencer sobre la utilidad práctica de sus proyectos.

106 «Nombramiento Real a Francisco Antonio Zea como primer profesor y encargado del gobierno y dirección del Real Jardín Botánico de Madrid,4 de abril de 1804». A.G.I., Sección Quinta, Audiencia de Santa Fe, legajo 667. "Oficio de Pedro Cevallos a Zea por el que le nombra sucesor de Cavanilles. Aranjuez, 11 de mayo de 1804,". A.J.B. Ref. I, 22, 1, 2. Comparte la dirección de los Anales de Historia Natural de Madrid, 11 de mayo de 1804.

107 Carta de Pombo a Mutis, Cartagena, 24 de octubre de 1804». A.J.B. III, 1,1, 275.

108 Zenón Alonso fue secretario del virrey Caballero y Góngora, secretario del Virrey Ezpeleta y funcionario del Consejo de Indias. Zenón Alonso era amigo personal de Cavanilles. Véase cartas de Zea, números 21, 22, 25, 27, 28 y 29.

${ }^{109}$ Pedro Cevallos trabajó en la Corte 44 años ocupando diferentes cargos. Inició su trabajo como Secretario de la Embajada de S. M. en Portugal en 1791. Después de ser Consejero de Hacienda y Ministro Plenipotenciario en Nápoles se le nombra el 28 diciembre de 1800 , Primer Secretario del Despacho y secretario de la Reina. El 7 de julio de 1808 firma la Constitución de Bayona, como representante del Consejo de Estado y Secretario de Despacho. Archivo Histórico Nacional. Sección Estado, Legajo 3423.

110 Godoy fue ministro de Carlos IV de 1789 a 1808. Véase, entre otros artículos de Zea, El Mercurio de Madrid en enero de 1803, y el Semanario de Agricultura y Artes, del jueves 18 de septiembre de 1806, pp. 186, 188, y 192. 


\section{Conclusión}

En este trabajo se destaca, por primera vez, la relación entre Francisco Antonio Zea y Antonio José Cavanilles. El análisis se fundamenta, principalmente, en la correspondencia inédita de Zea donde se pudo establecer la amistad que les unió en los aspectos políticos y académicos.

Zea ocupo un lugar importante en la polémica que tenía entablada Cavanilles con Ortega y el grupo de los peruanos. El criollo se puso al servicio del botánico Cavanilles aportando sus conocimientos sobre las plantas americanas y, en especial, utilizando su pluma y desarrollando una la labor de «intrigante» en los medios científicos franceses.

El escrito inédito de la Corneja es quizá uno de los elementos que mejor demuestra hasta que punto Zea se comprometió con Cavanilles en la polémica contra Ortega. Este escrito, que posiblemente era la segunda parte de los ya conocidos documentos de la controversia, no se llegó a publicar porque a Zea le dio miedo las represalias de Ortega contra sus proyectos americanos. Pero a pesar de tales circunstancias el criollo no dejó de impugnar en sus escritos y de combatir este grupo especialmente durante su estancia en el país galo.

Por su parte Cavanilles orientó la vida académica de Zea. Primero, en su ingreso como estudiante al Instituto Nacional de Francia y luego cuando lo compromete con el nombramiento de segundo profesor en la cátedra de botánica del Real Jardín y de segundo redactor de La Gaceta y El Mercurio de Madrid.

También puede detectarse una influencia notable del grupo de amistades de Cavanilles a las que se integró con gran facilidad Zea. Si se preguntase cuál fue el motivo que unió a Cavanilles con Zea resulta evidente que prevaleció la relación política que se mira en las controversias botánicas de la época frente al grupo de Ortega.

Finalmente, aunque no deja de ser paradójico, Zea, a la muerte de su amigo y protector Antonio José Cavanilles, le sustituye en la dirección del Real Jardín Botánico de Madrid. 


\section{ANEXOS \\ Primera carta de Zea a Cavanilles. Cádiz, 20 de junio de $1798^{1}$.}

«Cádiz, 20 de junio de 1798

Muy señor mío: mi afición a la Botánica y la circunstancia de ser discípulo de Dn. Joséph Celestino Mutis, grande amigo y corresponsal de Vm., disculparán mi atrevimiento en solicitar sus luces y consejos para adelantar mis conocimientos Botánicos.

Desde mi arrivo á España (hace dos años) quise manifestar a Vm. la veneración y aprecio con que siempre hé mirado sus escritos y persona, y el deseo de aprovecharme de su experiencia é instrucción. El abatimiento de mi suerte y la esperanza de mejorarla de un día á otro me han retenido tanto tiempo, hasta que cansado de luchar con mi destino, me he abandonado á él y solo pienso en adelantar mis conocimientos á pesar de las angustias de mi situación. Con ese objeto escribo á Vm. suplicándole no se desdeñe de guiarme en una carrera que Vm. ha corrido tan gloriosamente. El Dr. Mutis que no cesa de exhortarme á continuarla creyendo por la predilección con que siempre me ha mirado, que pueda en ella, valer alguna cosa, tendrá increíble gusto cuando sepa que lo hago baxo la dirección y consejos de su ilustre amigo. Puede ser que Vm. no pierda de el todo su trabajo, y que si logro volver a mi país, á quien Mutis llama la capital de la Flora, tenga Vm. un corresponsal formado de su mano, que seguramente se esmerará en manifestar su reconocimiento

He visto el Prodromo de la Flora Peruana y la colección de papeles sobre las controversias que han suscitado á Vm. la embidia y la ignorancia. Remiti á Mutis ambas obras y espero con impaciencia su contestación. Ya me figuro la impresión que le habrá hecho la idea extravagante de dedicar un genero á dos sujetos distintos, formando un nombre hermafrodita que no lo - pusiera mejor el mismo Fr. gerundio. No son menos ridículos los nombres compuestos de nombre y apellido, expuestos por otra parte á confundir las ideas de los formados de dos apellidos, como el Juan-Ulloa que parece compuesto de nombre y apellido, y es capaz él solo de deslucir un Prodromo bien hecho. Este por cualquier parte que se le mire, es una producción informe, que á la verdad no da honor á la Botánica española ni acredita un gusto literario. Yo querría que $\mathrm{Vm}$. les hubiere tratado con menos indulgencia, no cierto por desearles mal, sino porque más escarmentados escribieren la Flora con tiento y reflexión. Por que sentiré mucho que la obra no corresponda, como

\footnotetext{
${ }^{1}$ Esta carta la responde Cavanilles el día 3 de julio de 1798. En la transcripción de la carta hemos mantenido la ortografía de la época.
} 


\section{DIANA SOTO ARANGO}

me lo temo con fundamento, á los gastos que se han hecho y á la idea que nos han hecho concebir de las utilidades que reportarán las Artes y el Comercio, Esto bien puede ser, pero la Botánica no creo que gane mucho, por las razones que expondré a Vm.

Mientras no se escriba una obra fundamental sobre la Botánica Americana, ó se publique para modelo la Flora de Bogotá, serán inevitables los yerros en la determinación de especies y variedades y aun en la de los géneros algunas veces, por más hábil que sea el observador. Es necesario mucho conocimiento de los diversos temperamentos de la América, de su varía fecundidad y otras circunstancias locales que influyen en las plantas más de lo que se cree, para no multiplicar especies que muchas veces no son más que variedades. Como no tengo algún libro de Botánica para refrescar las ideas, no puedo hablar con exactitud; pero entre muchos ejemplos que pudiera citar me acuerdo de una Hiraca de Sacquin, que en unos temperamentos aparece triphylla, diphylla en otros y en muchos con hojas sencillas y dos estipulas en el peciolo, que si mal no me recuerdo, es como la observó su descubridor. Ya se deja ver que la figura, superficie, pubescencia, ángulos de las hojas variarán notablemente en estos tres temperamentos, siendo muy natural que en las hojas de tres en rama se halle la hoja central angostada por uno y otro lado hacia la base y los laterales por el lado interior: que las hojas sencillas serán mucho más grandes, más bien proporcionadas y guarden la disposición y figura á que naturalmente propenden, y que las de tres o dos en rama pierden por vivir en sociedad. Al pasar de un temperamento á otro se ve distintamente el efecto de esta variación, insensible al observador, va produciendo en esta y otras muchas plantas de modo que de esta sola Hiraca haría qualquiera cinco ó seis especies, de los quales tres á penas serían variedades y las otras no merecen la atención de el Botánico, sino en quanto es observación.

He puesto a $\mathrm{Vm}$. un ejemplo de que me acuerdo, aunque no tan claramente como sería preciso para formar ideas exactas sobre las frequentes variaciones de las plantas Americanas. En general se nota que la pubescencia varía a cada paso: que las hojas degeneran en las figuras afines y aun en otras muy diversas: que su magnitud, composición, proporciones de estar sujetas a mil alternativas: que los receptáculos, de tanto uso en la Singenesia, exponen á muchos yerros en la determinación de los géneros, siendo frequente volverse converso el plano, aovado ó cónico el converso \& \& \&. Todo lo cual añadido al razio porte ó cuerpo de las plantas, siendo aquí débil y pequeño arbusto el que más allá es un árbol corpulento y robusto, nos induce al error. He desconocido cien veces la Polygala Senega, que es una de las primeras plantas que conocí y con quien estaba familiarizado, por ser tan común en Santafé, que apenas se da un paso sin encontrarla.

Ruiz que tanto ha declamado contra las descripciones hechas por plantas secas ó degeneradas en los jardines i que dirá quando se les haga ver que él mismo las describe degeneradas en su propio suelo?. Por que nada hace el caso que las plantas degenere por cultura ó por la extraordinaria fecundidad del terreno.

Es cierto que no habiendo publicado aun el primer tomo de las especies, no podemos asegurar que no haya tenido presentes estas observaciones $y$, guiándose por ellas; pero no encontrándose en sus escritos ni en el Prodro- 


\section{CAVANILLES Y ZEA: UNA AMISTAD POLITICO-CIENTIFICA}

mo mismo alguna expresión que lo indique y habiéndole ya visto en la quimología dar por especies variedades y describir el Minoxylon Perniferum en términos de poderse dudar que lo haya visto, no es temeridad pensar que habrá lindas cosas en la Flora. Deseo engañarme en mi concepto, no solo por el bien de la ciencia, sino también por el honor de la Nación, en cuya gloria botánica me intereso mucho.

Me admira que trabajando en una obra de tanta importancia y en la que fundan seguramente el crédito, no se hayan provisto de los libros necesarios y carezcan de las noticias más conducentes á su objeto. Prescindo de la poca demora en sacar los caracteres que llaman diferenciales y que en los géneros que conosco están generalmente formados de notas despreciables, y me paro solamente en la reflexión de que á estos hombres todo les coge de nuevo. No solamente ignoran los géneros recientemente establecidos con el nombre de algunos Botánicos á quienes dedican los suyos, sino que aun el dedicado hace doce ó más años á su maestro Ortega, reproduciéndolo con el nombre de Nentería, lo han desconocido. Es cierto que Linné se equivocó estampando Gomozia en lugar de Gomezia, como Betaria en lugar de Bejaría en el dedicado á Bejar, Botánico de Cádiz; pero esta ligera alteración del nombre no creo que les disculpe. Bien claramente se conoce ha de ser tomado de algún Botánico el nombre que no siendo griego ni latino, fue puesto ó aprobado por el mismo que estableció no se admitiesen otros en Botánica. Ademas de que al publicar el genero es muy regular que Linné haya advertido á quien se dedicaba.

Los efugios que Ruiz ha buscado para sostener que sus géneros Acunna y Stereoxylon no son especies de Befuria y Escallonia, son pruebas contra su propio dictamen. Precisamente se encuentran en la B. vesinosa y creo que también con la B. vrenu, los que llama poros en las antenas. No es este un carácter, como en el Solamun; es una nota despreciable que ni en el caracter natural hay necesidad de expresarla. Las antenas se abren obliquamente por el ápice, y esta abertura es más ó menos extensa según la cantidad del pollen y el vigor de la vegetación. A veces se rompe o abre toda la antena. Por lo que hace al fruto es el mismo puntualmente que describe Ruiz, con la diferencia de que por no haber un termino preciso para este pericarpio, Mutis lo llama baya seca y él, si bien me acuerdo, caxita. En efecto es un pericarpio que solo difiere de capsula en no tener ventallas, que es la razón por que Mutis lo ha llamado baya seca. Lo mismo a la letra sucede en el genero Escallonia, con la diferencia de ser Herible y suave, y no árido como en la Betaria; pero ambos carecen de pulpa. Las figuras del Prodromo representan la fructificación en su magnitud natural y tan exactamente que por ellas las reconocí, antes de ver la descripción.

Por lo que hace a los géneros de Vm. y a sus descripciones, contra las quales veo conjurados a casi todos los Botánicos de España, puede Vm. tener la satisfacción de ser acaso el que más ha acertado en las plantas Americanas. Hemos encontrado muchas de las que Vm. ha ilustrado en sus escritos (Frichilias, Guareas, Malpighias, Banisterías, \& \& \&) y muchas veces no hemos tenido que añadir ni corregir una palabra, dexando intacta la descripción, lo que apenas hay escritor de aquellas plantas a quien le suceda. No me acuerdo jamas de haber encontrado un error positivo, como en todos los que han 


\section{DIANA SOTO ARANGO}

hablado de ellas. El genero Ferrapteris, que ha dado tanto que hablar, me parece tan necesario que sin el sería una confusión la que resultaría en las Banisterías, no habiendo más razón para suprimir a este que a otros nuevos establecidos por el numero de alas hasta concluir en el Polypteris. Yo no se lo que hará Mutis en este particular; pero me parece deben establecer estos géneros y creo haberle oído alguna cosa. Mucho más bien atendiendo a las muchas Banisterías que se han descubierto allí. Entre ellas hay no pocas que carecen de los estigmas foliosos con que Vm. dice se podrían distinguirse de las Malpighias, en caso de convenir este carácter a todas las especies. Ni verdaderamente son foliosos los estigmas, en las que aparecen tales, sino los estilos; pero esta observación no podía hacerse sino en las plantas vivas.

En otra ocasión daré a Vm. por mayor una idea de las producciones vegetales de aquel país, tan rico en estas preciosidades, y de la Flora que ha de inmortalizarlo.

Es natural que Vm. quiera saber quien soy yo que tanto admiro sus escritos y que le he dado tan mal rato. Yo he nacido en la Provincia de Antioquía en el Reino de Santafé. Estudiaba Leyes en aquella Universidad, en la qual era catedrático de Humanidades, quando Mutis fue a solicitarme, o como dice el mismo en su informe al Rey, a conquistarme para la Botánica. En efecto fui por su solicitud agregado á su Expedición con el destino de sucederle en la Dirección de ella y continuar sus obras. Dos años estuve en su casa instruyéndome en la Facultad, y otro pasé en una montaña solitaria haciendo excursiones botánicas. De allí fue a sacarme la calumnia de algunos enemigos, que algunas distinciones obtenidas en la Universidad y la que debí a Mutis en competencia de muchos pretendientes, me habrán conciliado. Hace dos años que estoy en Cádiz esperando a que se acuerden de hacerme justicia y restituirme a mis estudios y tarea. Entre tanto tengo la satisfacción de que las tramas de mis enemigos no me hayan privado de la amistad del D. Mutis, por más que lo intentaron.

Deseo a Vm. toda felicidad y soy su más apasionado servidor.

Q. B. S. M.

Francisco Antonio Zea

S. D. Antonio Joséph de Cavanilles» 